\title{
La función cultural de los museos en San Salvador
}

Carmen Molina Tamacas

El presente artículo es un resumen de la tesis "La función cultural de los museos de San Salvador", para optar al grado de licenciatura en Antropología por la Universidad Tecnológica de El Salvador, Utec. El estudio, desarrollado en el transcurso de 2008, explora el legado material e intelectual de nueve museos que tienen su sede en San Salvador.

El objetivo general, planteado al inicio de la investigación, fue determinar, por medio de un análisis de carácter diacrónico, cuál es la función cultural que desempeñan los museos en la actual sociedad salvadoreña, así como exponer su quehacer social y cultural y la relación que tienen con el público visitante.

Al respecto, se fijaron los siguientes objetivos específicos:

a) Desde una perspectiva antropológica, explicar cuál es la idea de museo que existe y qué entiende la sociedad urbana salvadoreña por museo.

b) Ante la ausencia de una clasificación oficial, determinar cuál es el enfoque de los museos de San Salvador.

c) Analizar, desde una perspectiva antropológica, cuál es la funcionalidad social y cultural de los museos y, si es posible, el grado de pertenencia que tienen los visitantes con ellos.

d) Reconstruir la historia del origen y desarrollo de los museos estudiados a partir de una investigación bibliográfica.

Los nueve museos ubicados en San Salvador son: el Museo Universitario de Antropología (MUA), de la Utec; el Museo de Arte (Marte); el Museo Nacional de Antropología "Dr. David J. Guzmán” (Muna); el Museo de la Palabra y la Imagen (Mupi); el Museo de Arte Popular (Iniciativa pro Arte 
Popular, Inar); Tin Marín, Museo de los Niños; el Museo de Historia Militar "Cuartel El Zapote"; el Museo de Historia Natural (MHNES), y el Museo del Fútbol. ${ }^{1}$

Dentro de la estrategia metodológica cabe destacar la utilización de métodos y técnicas de las investigaciones antropológicas, entre las que figuraron la consulta de abundante bibliografía; es decir, documentos, libros, folletería y publicaciones tanto en forma física como virtual, lo cual constituyó el eje transversal de esta investigación; se realizaron continuas visitas en cada museo, con un objetivo especial en cada una de ellas: observar el entorno y la interacción entre los trabajadores del museo, sus autoridades y el público. Así mismo, se elaboró un guión básico para las entrevistas abiertas no estructuradas, con el objetivo de facilitar la expresión de las opiniones, hechos personales, recuerdos y detalles íntimos de las personas entrevistadas. ${ }^{2}$

La interpretación de los datos técnicos, legales, administrativos, históricos y científicos que atañen a los museos, obtenidos durante la fase de recolección de información bibliográfica, así como en el proceso de realización de entrevistas y la observación de campo será desarrollada a continuación. El análisis, con base en el marco teórico, fue realizado con un enfoque diacrónico; es decir, los resultados se presentan de acuerdo con la evolución de los hechos o procesos históricos a lo largo del tiempo.

Al interior del marco teórico, se partió de la idea de que los museos son instituciones sociales cuyo concepto es una "realidad dinámica que continúa desarrollándose" desde el siglo XVI hasta nuestros días, tal como lo plantean autores como Francisca Hernández Hernández, directora académica del Máster de Museología de la Universidad Complutense de Madrid. ${ }^{3}$

También, se toma como base el concepto de museo creado por el International Council of Museums (Icom): museo es "todo establecimiento permanente,

\footnotetext{
1 Un Museo del fútbol no existe como institución establecida, privada o gubernamental. Durante esta investigación fue inaugurado el "Fútbol Fest" en el Centro Internacional de Ferias y Convenciones. Esta actividad, de carácter comercial, duró del 10 al 12 de diciembre de 2008 e incluyó un espacio denominado como "museo". La taquilla del evento fue a beneficio de la Fundación Mágico González.

2 En total se realizaron 42 entrevistas, tanto de personas internas como externas de los museos. Entre la categoría interna figura personal técnico y administrativo así como personas que con anterioridad han trabajado estas instituciones; en el área externa fueron incluidos básicamente visitantes y público en general.

3 Hernández Hernández, F., Manual de Museología. Editorial Síntesis. Madrid. Pág. 62.
} 
administrado en beneficio del interés general para conservar, estudiar, hacer valer por medios diversos y sobre todo, exponer para deleite y educación del público un conjunto de elementos de valor cultural: colecciones de objetos artísticos, históricos, científicos y técnicos, jardines botánicos y zoológicos y acuarios. Las bibliotecas públicas y los centros de archivos que mantienen salas de exposición de manera permanente, serán asimilados a los museos". ${ }^{4}$

Es importante destacar que cada texto que aborda el tema de los museos construye un concepto sobre lo que es o debería ser esta institución. Al respecto, y después de citar diversos referentes teóricos, esta tesis aporta la siguiente definición: "Los museos son instituciones permanentes que resguardan objetos a los cuales los científicos les atribuyen cualidades simbólicas y utilitarias producto de procesos históricos y culturales que han acontecido en sociedades determinadas. Entre las misiones que los museos tienen para con estas colecciones es conservarlas, inventariarlas, protegerlas y exhibir las investigaciones en torno a esos significados, contribuyendo así a la difusión de estos valores con el propósito de fortalecer la apreciación y apropiación del patrimonio cultural de la sociedad a la que pertenecen. Los museos desempeñan muchos papeles en la sociedad: económico, académico, político, científico y de recreación, entre otros".

En el marco histórico - que constituye un capítulo completo de la investigación - se aborda, de manera extensa, el desarrollo del museo, desde la antigüedad hasta el presente, tomando como base dos conceptos que se relacionan de manera directa: la expoliación y el coleccionismo.

Según el arquitecto salvadoreño Óscar Batres, el despojo de los bienes materiales de un país, con afán de conquista y colonización, existe desde tiempos remotos. Él indica que "expoliación" tiene una connotación estrictamente violenta; pero como se verá más adelante, al analizar el papel de la antropología en el colonialismo, este proceso también pudo ocurrir de una manera más sutil.

Batres se refiere a la expoliación como la forma violenta de despojar con injusticia. "Es atribuirse pertenencias ajenas, quitando posesiones bajo la influencia del poder o de la fuerza... Ese fue el panorama que se dibujó en la

4 Fernández, Luis A. Museología. Introducción a la teoría y práctica del museo. Ediciones Istmo. Madrid. 1993. Pág. 34. 
Roma antigua”, y que eventualmente se suscita incluso en nuestros días. Por ejemplo, menciona que durante los siglos XIII y XIX, tanto en Europa como en América, se realizaron grandes expediciones comandadas por investigadores académicos, que bajo la influencia del poder y acciones clandestinas saquearon muchos lugares de dichos continentes. En la actualidad hay referencias documentadas de que grandes y reconocidos museos son depositarios de colecciones muy importantes que han sido producto del expolio realizado en épocas pasadas por parte de países que tuvieron dominio sobre otros ejerciendo el saqueo de objetos de interés cultural. ${ }^{5}$

Así mismo, posiblemente como consecuencia primero del coleccionismo, se desarrolló con el tiempo y hasta el presente, siendo considerado como básico y fundamental en cuanto constituye el génesis del patrimonio de un museo, por pequeño, grande, complejo o especializado que sea.

Dado el carácter de este estudio, se subrayan aspectos relevantes como la relación de la Antropología con los museos y la creación del Museo Nacional en 1883.

Diversas publicaciones periodísticas y académicas, como el artículo "El boom de los museos en El Salvador"“ que apareció en la "Revista Dominical" de La Prensa Gráfica, en el 2002; los escritos del antropólogo salvadoreño Ramón Rivas y de la cátedra universitaria del arquitecto y museógrafo Óscar Batres coinciden en que la década más reciente ha registrado un auge en el interés de la población salvadoreña por conservar y exhibir objetos, documentos y fotografías que explican la razón de ser de un pueblo o de un conglomerado.

Esto responde, de acuerdo con Rivas, a la necesidad de que "el deseo de encontrarse con la identidad se hace constante en todas las esferas de la sociedad". 7

\footnotetext{
5 Al respecto, ver el apartado "Antecedentes del museo" del folleto Historia de los museos utilizado en la cátedra de Museología en la Universidad Tecnológica de El Salvador, proporcionado por el arquitecto Óscar Batres, 2006.

6 Así lo relató Ada Montalvo en la "Revista Dominical" de La Prensa Gráfica: "Este aniversario (del Museo Nacional de Antropología) ocurre en medio de un boom 'museístico', que incluye la próxima apertura del Museo Militar, el de Historia Nacional y el de Arte Moderno".

7 Rivas, R., Ensayo sobre estudios antropológicos en El Salvador. Documento inédito. San Salvador, El Salvador. 2009.
} 
En El Salvador, la firma de los Acuerdos de Paz, en 1992, marca un momento decisivo para la actividad cultural, en particular para los museos, ya que diversas iniciativas salen a la luz.

\section{Los resultados}

Al contraponer la rigurosa teoría museológica con la realidad manifestada por los técnicos y empleados y los visitantes de algunos de los museos más representativos de San Salvador, es pertinente acotar que los museos sí desempeñan los papeles y funciones que estipula la teoría, pero con serias limitantes.

Hace falta que los habitantes de San Salvador y sus alrededores desarrollen una cultura por los museos. Sólo así la apropiación y la demanda de sus servicios empujará la transformación de estas instituciones, algunas de las cuales permanecen estáticas mientras revoluciones culturales - como la que propician las tecnología de la información y la crisis económica- ocurren a su alrededor.

Es pertinente concluir, con base en la información obtenida de las personas entrevistadas para este estudio antropológico, que San Salvador carece de una cultura de museos bien desarrollada. Por un lado, la mayoría de museos de la capital carecen de una plantilla completa de personal para llevar a cabo todas las tareas que deben realizarse; en algunos casos, por ejemplo, hacen falta investigadores, mientras que en otros museos no hay conservadores de planta o carecen de guías permanentes para atender al público.

En cuanto a los visitantes, uno de los hallazgos de este estudio es que muchas personas que se deciden por visitar los museos lo hacen por vez primera. Si son adultos, recuerdan que lo hicieron en sus años escolares; si son jóvenes, por lo general lo hacen para cumplir con una tarea específica; y si son niños, lo hacen acompañando a sus padres. En estos casos, los menores están expuestos a los museos con la frecuencia que deciden las autoridades de los colegios y escuelas a las que asisten. La falta de una cultura de museos en San Salvador se traduce en la ausencia del sentimiento de "apropiación" por parte de los ciudadanos hacia los museos.

Pese a que no es una tradición que los salvadoreños visiten asiduamente los museos, cuando lo realizan, especialmente en grupos familiares, ocurren dinámicas culturales que pasan casi inadvertidas, como la transmisión oral de 
conocimientos ancestrales. Los adultos explican a los niños, con base en su experiencia y recuerdos, lo que tal o cual objeto significa. En ese caso, los museos cumplen su función, aunque de manera parcial, de ser "mediadores culturales".

El surgimiento del museo como una de las instituciones culturales más antiguas de El Salvador, como es el caso del Museo Nacional "David J. Guzmán" -que desde finales de los años 90 fue renombrado como Museo Nacional de Antropología - obedeció a una perspectiva mercantilista, alejada de la corrientes científicas sobre el conocimiento humano que propugnaban el conocimiento "de los otros", tal es caso de otros museos en Europa. Esa perspectiva cambió a finales de los años 70, cuando un grupo de jóvenes académicos desempeñó una actividad de investigación y difusión hasta ahora irrepetible; pero la guerra (1980-1992) ocasionó una ruptura con la institucionalidad que había sido establecida. De manera que hasta ahora, pese a que fue reconstruido, el Museo Nacional permanece con la misma museografía de hace siete años. Muchas de las iniciativas que fueron planificadas e iniciadas en la década de los 80, se han olvidado, no por falta de interés, sino por la inseguridad que reinó en esa época.

La memoria histórica de los museos en San Salvador se conserva en las personas que están vivas. Por problemas de recursos económicos, y otros limitantes, existen muy pocos documentos que hablen de la historia de los museos capitalinos desde la perspectiva de quienes han trabajado años y hasta décadas en ellos. Este trabajo da pruebas de esto. Es deber de los historiadores, antropólogos, arqueólogos y conservadores del patrimonio preservar esa memoria por medio de programas o trabajos de documentación permanente sobre la producción intelectual que en estos lugares se realiza.

El auge y la accesibilidad de las nuevas tecnologías de la información plantean retos muy fuertes para los museos capitalinos, ya que la mayoría carece de estas herramientas que condicionan nuestra forma de comunicación contemporánea.

Así como está anclada la visión de que los museos solamente reflejan el pasado, este estudio también encontró mucha frustración en los técnicos que trabajan en ellos debido a que diversos factores como la burocracia y la carencia de recursos económicos impiden convertir en exhibiciones decenas de investigaciones que se han llevado a cabo. 
¿Cuál es la importancia que tienen los museos para la Antropología?, y, además, ¿cuál es la importancia que la Antropología representa para los museos?

En primer lugar, los museos de San Salvador custodian colecciones que constituyen el legado material no solo de la capital, sino del país. Por ende, estas instituciones conforman una fuente de información de primer orden para presentes y futuros estudios de carácter antropológico, histórico, arqueológico, educativo, artístico y de ciencias naturales. Los museos almacenan objetos con mucho simbolismo, de manera que atesoran retazos de la identidad nacional que pide a gritos ser descubierta. Es posible que en estas colecciones se encuentren las respuestas a muchas preguntas que los científicos realizan en el momento de estudiar los hechos sociales del presente, e incluso del pasado. En correspondencia, la Antropología - por medio de sus métodos de investigación - constituye la herramienta científica mediante la cual pueden encontrarse las respuestas a estas preguntas. Los antropólogos no solo nacionales, sino extranjeros, son los llamados a buscar, dentro de esas colecciones, la "materia prima" para sus reflexiones, las cuales derivarán en conocimiento de la realidad salvadoreña.

Por la trascendencia en la historia cultural de El Salvador, es necesario que la academia se interese por documentar el desarrollo del Museo Nacional de Antropología "David J. Guzmán”. Pero no solo describiendo los hechos o acontecimientos más relevantes de una manera cronológica, sino la implicación de las políticas públicas de su contexto, la producción de ideas y pensamiento científico en su interior. Con el argumento de que el Ministerio de Hacienda no otorga plazas — según las actuales autoridades estatales - el Muna funciona sin el aporte de antropólogos contratados a tiempo completo. Una futura tesis o investigación podría desentrañar la razón histórica de esta situación.

\section{Referentes bibliográficos}

Batres Posada, O., Los museos. Folleto didáctico para la cátedra de Museología. Universidad Tecnológica. El Salvador. 2006.

Fernández, L., Museología. Introducción a la teoría y práctica del museo. Ediciones Istmo. Madrid, España. 1993.

Hernández, Hernández, F., Manual de Museología. Editorial Síntesis. Madrid, España. 
Montalvo, A., El boom de los museos en El Salvador. "Revista Dominical" de La Prensa Gráfica. El Salvador, 12 de octubre de 2002.

Rivas, Ramón, Ensayo sobre estudios antropológicos en El Salvador. [Digital]. Documento inédito, en proceso de publicación. El Salvador. 2009.

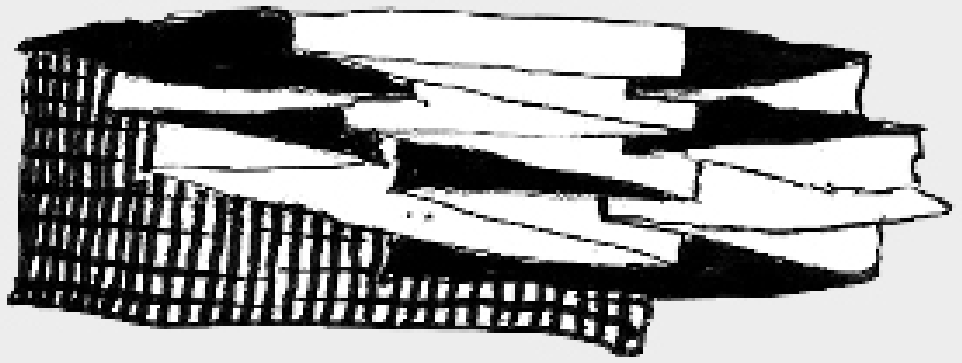

